\title{
Risk factors for cardiac arrhythmias in children with congenital heart disease after surgical intervention in the early postoperative period
}

Joanna Rękawek, MD, ${ }^{a}$ Andrzej Kansy, MD, ${ }^{b}$ Maria Miszczak-Knecht, MD, ${ }^{a}$ Małgorzata Manowska, MD, ${ }^{c}$ Katarzyna Bieganowska, MD, PhD, ${ }^{a}$ Monika Brzezinska-Paszke, MD, ${ }^{a}$ Elżbieta Szymaniak, MD, ${ }^{a}$ Anna Turska-Kmieć, MD, ${ }^{a}$ Przemysław Maruszewski, MD, ${ }^{\mathrm{b}}$ Piotr Burczyński, MD, PhD, ${ }^{\mathrm{b}}$ and Wanda Kawalec, MD, PhD

From the Departments of Cardiology, ${ }^{\text {a }}$ Cardiac Surgery, ${ }^{\mathrm{b}}$ and Anesthesiology, ${ }^{\mathrm{c}}$ Children's Memorial Health Institute, Warsaw, Poland.

The study was approved by the Ethical Committee of the Children's Memorial Health Institute and supported by an internal grant of the Children's Memorial Health Institute (Grant No. 84/05).

Received for publication July 29, 2006; revisions received Nov 28, 2006; accepted for publication Dec 13, 2006.

Address for reprints: Joanna Rẹkawek, MD, Department of Cardiology, Children's Memorial Health Institute, Al. Dzieci Polskich 20 04-830 Warsaw, Poland (E-mail: j.rekawek@czd.pl).

J Thorac Cardiovasc Surg 2007;133:900-4 $0022-5223 / \$ 32.00$

Copyright (๑) 2007 by The American Association for Thoracic Surgery

doi:10.1016/j.jtcvs.2006.12.011
Objective: Early postoperative arrhythmias are a recognized complication of pediatric cardiac surgery.

Methods: Diagnosis and treatment of early postoperative arrhythmias were prospectively analyzed in 402 consecutive patients aged 1 day to 18 years (mean 29.5 months) who underwent operation between January and December 2005 at our institute. All children were admitted to the intensive care unit, and continuous electrocardiogram monitoring was performed. Risk factors, such as age, weight, Aristotle Basic Score, cardiopulmonary bypass time, aortic crossclamp time, and use of deep hypothermia and circulatory arrest, were compared. Statistical analysis using the Student $t$ test, Mann-Whitney $U$ test, or Fisher exact test was performed. Multivariate stepwise logistic regression was used to assess the risk factors of postoperative arrhythmias.

Results: Arrhythmias occurred in 57 of 402 patients (14.2\%). The most common types of arrhythmia were junctional ectopic tachycardia (21), supraventricular tachycardia (15), and arteriovenous block (6). Risk factors for arrhythmias, such as lower age $\left(P=.0041^{*}\right)$, lower body weight $\left(P=.000001^{*}\right)$, higher Aristotle Basic Score $\left(P=.000001^{*}\right)$, longer cardiopulmonary bypass time $\left(P=.000001^{*}\right)$, aortic crossclamp time $\left(P=.000001^{*}\right)$, and use of deep hypothermia and circulatory arrest $\left(P=.0188^{*}\right)$, were identified in a univariate analysis. In the multivariate stepwise logistic regression, only higher Aristotle Basic Score was statistically significant $\left(P=.000003^{*}\right)$ compared with weight $(P=.62)$ and age $(P=.40)$; in the cardiopulmonary bypass group, only longer aortic crossclamp time was statistically significant $(P=.007 *)$.

Conclusion: Lower age, lower body weight, higher Aristotle Basic Score, longer cardiopulmonary bypass time, aortic crossclamp time, and use of deep hypothermia and circulatory arrest are the risk factors for postoperative arrhythmias. Junctional ectopic tachycardia and supraventricular tachycardia were the most common postoperative arrhythmias.

$\mathrm{P}$ ostoperative arrhythmias were a major cause of mortality and morbidity after cardiac surgery for congenital heart disease. ${ }^{1}$ In the early postoperative period after cardiac surgery, patients with congenital heart disease are especially vulnerable to rhythm disturbances. There have been numerous reports published about arrhythmia as a late complication of surgical procedures, such as the Mustard or Senning operation for transposition of the great arteries, Fontan procedures, or tetralogy of Fallot repair. ${ }^{2-5}$ Although data concerning cardiac arrhythmias in

*P value statistically significant. 


$$
\begin{aligned}
& \text { Abbreviations and Acronyms } \\
& \begin{aligned}
\mathrm{AV} & =\text { atrioventricular } \\
\mathrm{CI} & =\text { confidence interval } \\
\mathrm{CPB} & =\text { cardiopulmonary bypass } \\
\mathrm{DHCA} & =\text { deep hypothermia and circulatory arrest } \\
\mathrm{ICU} & =\text { intensive care unit } \\
\mathrm{JET} & =\text { junctional ectopic tachycardia } \\
\mathrm{SD} & =\text { standard deviation } \\
\mathrm{SVT} & =\text { supraventricular tachycardia }
\end{aligned}
\end{aligned}
$$

children in the early postoperative period are not common in the literature, the year 2002 was abundant in studies concerning this problem. ${ }^{6-8}$

The aim of this prospective study was to determine the incidence of early postoperative arrhythmias in a group of pediatric patients after cardiac surgery and to analyze the risk factors of developing such condition.

\section{Materials and Methods}

All 402 consecutive cases analyzed in this study concerned the treatment of pediatric patients undergoing surgery for congenital heart disease in the Department of Cardiac Surgery of the Children's Memorial Health Institute from January to December 2005.

A total of 200 girls and 202 boys underwent an open surgical procedure (cardiopulmonary bypass $[\mathrm{CPB}]$ ) or non-open surgical procedure (non-CPB). Down syndrome was additionally diagnosed in 6 children. All patients were admitted to the intensive care unit (ICU) of our institute, and continuous electrocardiogram monitoring was used. Storage and retrospective printing of electrocardiograms were not available for the purpose of the study. In all cases of cardiac arrhythmia detected in the ICU, a standard electrocardiogram was performed and analyzed by pediatric cardiologist to verify the diagnosis.

\section{Arrhythmia Definition}

Arrhythmias were classified as junctional ectopic tachycardia (JET), supraventricular tachycardia (SVT), premature supraventricular contractions, premature ventricular contractions, third-degree heart block, atrial flutter, sinus bradycardia, junctional escape rhythm, sinus tachycardia, ventricular tachycardia, and ventricular fibrillation. JET was defined as a narrow complex tachycardia with atrioventricular (AV) dissociation. SVT was defined as AV reentrant (retrograde $\mathrm{P}$ wave) or 1:1 AV conduction. Atrial flutter was defined as a narrow complex tachycardia with greater than $2: 1$ conduction. Frequent premature supraventricular or ventricular beats were diagnosed if their number exceeded 10 per minute. Sinus bradycardia was defined as a sinus rhythm with a rate too low for a particular age and hemodynamic condition or a junctional escape rhythm in the absence of AV block or JET. The following minimal rates according to age were considered as bradycardia: 120 to 130 beats/min diurnal rate in neonates, less than 120 beats/min in children aged less than 1 year, 110 beats/min in children aged 3 to 4 years, 100 beats $/ \mathrm{min}$ in children aged 5 to 7 years, less than 90 beats/min in children aged 8 to 11 years, and 85 beats/min in children aged 12 to 15 years. ${ }^{9}$

\section{Arrhythmia Management}

All reversible causes of arrhythmia, such as electrolyte or metabolic disturbances, were corrected. The following indications for treatment were identified: JET, SVT, AV block, junctional escape rhythm, and sinus bradycardia.

Amiodarone was our drug of choice for both supraventricular and ventricular tachycardia. An initial single $5 \mathrm{mg} / \mathrm{kg}$ intravenous dose of amiodarone was then followed by intravenous infusion of 10 to $15 \mathrm{mg} / \mathrm{kg}$ per day. No adverse effects of intravenous amiodarone therapy, such as hypotension or proarrhythmogenic effect, were observed. Liver and thyroid laboratory values remained within normal limits.

Patients with AV blocks or junctional escape rhythm were paced using temporary electrodes implanted during every surgical procedure. Permanent pacing was performed in all cases of $\mathrm{AV}$ block more than 7 days. ${ }^{10}$

Collected data included patient's age and gender, type of cardiac malformation, type of surgical procedure performed, and the Aristotle Basic Score of the procedure.

The Aristotle Basic Score is a complexity scoring system for congenital heart surgery. The score is based on mortality, morbidity, and surgical difficulty assigned to the primary procedure. ${ }^{11,12}$

\section{Statistical Analysis}

Descriptive statistics are reported as mean value and $95 \%$ confidence interval (CI). Comparisons between groups were made using the unpaired Student $t$ test or Mann-Whitney $U$ test where appropriate. Discrete variables were compared with the Fisher exact test. Multivariate stepwise logistic regression was used to assess the risk factors of postoperative cardiac arrhythmias. Statistical analysis was performed using Statistica for Windows software (StatSoft Inc, Tulsa, Okla).

\section{Results}

The mean age at procedure was 29.5 months (95\% CI 24.9-34.1, standard deviation [SD] \pm 46.8). The mean body weight was $11.8 \mathrm{~kg}$ (95\% CI 10.5-13.1, SD \pm 13.3$)$, and the mean Aristotle Basic Score was 6.4 (95\% CI 6.26.6, $\mathrm{SD} \pm 2.2$ ).

Cardiac arrhythmia was diagnosed in 57 of 402 cases (14.2\%), 53 of 299 CPB procedures (17.7\%) and 4 of 103 non-CPB procedures $(3.9 \%)$.

Table 1 presents the potential risk factors for arrhythmias and perioperative details.

Postoperative arrhythmias occurred in 12 of 38 patients $(31.58 \%)$ when deep hypothermia and circulatory arrest (DHCA) was used during CPB, compared with 41 of 262 patients $(15.65 \%)$ when DHCA was not used $(P=.0188)$. Longer DHCA time is not associated with a higher incidence of arrhythmias $(P=.24)$. The onset of postoperative arrhythmias is associated with prolonged intermittent positive pressure ventilation time $(P<.000001)$, prolonged ICU stay $(P<.000001)$, and higher hospital mortality $(P=.035)$.

After a surgical procedure involving opening the right ventricular outflow tract, a ventricular tachycardia progressing to ventricular fibrillation was identified as the cause of 
TABLE 1. Potential risk factors for arrhythmias and perioperative details

\begin{tabular}{lccc}
\hline & Arrhythmic group & Non-arrhythmic group & $P$ value \\
\hline Age (mo) & $18.74,95 \% \mathrm{Cl}(84-29.1), \mathrm{SD} \pm 39.04$ & $31.23,95 \% \mathrm{Cl}(26.8-46.3), \mathrm{SD} \pm 47.7$ & .0041 \\
Body weight (kg) & $8.96,95 \% \mathrm{Cl}(5.9-12.0), \mathrm{SD} \pm 11.53$ & $12.27,95 \% \mathrm{Cl}(10.8-13.7), \mathrm{SD} \pm 13.53$ & .0078 \\
Aristotle Basic Score (402 patients) & $7.8,95 \% \mathrm{Cl}(7.3-8.3), \mathrm{SD} \pm 1.9$ & $6.22,95 \% \mathrm{Cl}(6.0-6.4), \mathrm{SD} \pm 2.14$ & .000001 \\
CPB time (299 patients) & $169.1,95 \% \mathrm{Cl}(150.1-188.2), \mathrm{SD} \pm 69.2$ & $128.7,95 \% \mathrm{Cl}(111.8-145.6), \mathrm{SD} \pm 134.9$ & .000001 \\
Aortic crossclamp time (294 patients) & $82.6,95 \% \mathrm{Cl}(72.2-92.9), \mathrm{SD} \pm 37.1$ & $53.6,95 \% \mathrm{Cl}(49.3-57.9), \mathrm{SD} \pm 34.2$ & .000001 \\
DHCA time (38 patients) & $29.0,95 \% \mathrm{Cl}(16.6-41.4), \mathrm{SD} \pm 19.6$ & $20.4,95 \% \mathrm{Cl}(13.7-27.1), \mathrm{SD} \pm 16.6$ & .24 \\
IPPV time (h) & $163.0,95 \% \mathrm{Cl}(105.0-221.0), \mathrm{SD} \pm 218.6$ & $76.2,95 \% \mathrm{Cl}(45.5-106.9), \mathrm{SD} \pm 289.6$ & .000001 \\
ICU stay (d) & $10.7,95 \% \mathrm{Cl}(6.9-14.6), \mathrm{SD} \pm 14.6$ & $5.1,95 \% \mathrm{Cl}(3.7-6.5), \mathrm{SD} \pm 12.9$ & .000001 \\
Hospital mortality & $9.26 \%(5 / 57)$ & $2.6 \%(9 / 345)$ & .035 \\
\hline
\end{tabular}

Values are presented as mean, $95 \% \mathrm{Cl}$, and SD. CPB, Cardiopulmonary bypass; DHCA, deep hypothermia and circulatory arrest; IPPV, intermittent positive pressure ventilation, $I C U$, intensive care unit; $C l$, confidence interval; $S D$, standard deviation.

hospital death on the first postoperative day in a patient with both aortic and pulmonary stenosis. Other deaths were not related to postoperative arrhythmias.

Table 2 presents the incidences of the types of cardiac arrhythmia corresponding to particular surgical procedures.
Table 3 presents the incidences of postoperative arrhythmia assigned to types of surgical procedure with the Aristotle Basic Score.

The most common cardiac arrhythmia was JET (21/57), followed by SVT (15/57). A third-degree AV block was

TABLE 2. Incidences of types of cardiac arrhythmia corresponding to particular diagnosis

\begin{tabular}{|c|c|c|c|c|c|c|c|c|c|c|c|}
\hline & 1 & 2 & 3 & 4 & 5 & 6 & 7 & 8 & 9 & 10 & All \\
\hline VSD perimembranous & 5 & 1 & & 1 & & & & & 2 & & 9 \\
\hline CAVSD & 5 & 1 & & & & & & & 1 & & 7 \\
\hline ToF & 2 & & 2 & & & 1 & & & 1 & 1 & 7 \\
\hline TGA, VSD & 2 & 2 & & & & & & & & & 4 \\
\hline TGA, IVS & & 2 & & & & & & & 1 & & 3 \\
\hline SV, DILV & 1 & 1 & & & & & & & 1 & & 3 \\
\hline SV, TA & & & & 1 & 1 & & & & & & 2 \\
\hline TAPVC, supracardiac & & & & & 1 & & & 1 & & & 2 \\
\hline AoR & & & & 1 & & 1 & & & & & 2 \\
\hline AoA hypoplasia & & 2 & & & & & & & & & 2 \\
\hline Interrupted AoA & & 2 & & & & & & & & & 2 \\
\hline ASD secundum & 1 & & & & & & & & & & 1 \\
\hline ASD sinus venosus & 1 & & & & & & & & & & 1 \\
\hline VSD, multiple & & 1 & & & & & & & & & 1 \\
\hline PAVSD & 1 & & & & & & & & & & 1 \\
\hline PAPVC, scimitar & 1 & & & & & & & & & & 1 \\
\hline PA, VSD & & & & & & & 1 & & & & 1 \\
\hline AoS, valvar & & & & & & 1 & & & & & 1 \\
\hline SV, heterotaxia syndrome & & 1 & & & & & & & & & 1 \\
\hline VSD, CoA & 1 & & & & & & & & & & 1 \\
\hline TGA, VSD LVOTO & & 1 & & & & & & & & & 1 \\
\hline cTGA, VSD & 1 & & & & & & & & & & 1 \\
\hline cTGA, VSD LVOTO & & & 1 & & & & & & & & 1 \\
\hline ALCAPA & 1 & & & & & & & & & & 1 \\
\hline RVOTO, PS, AoS & & & & & & & & 1 & & & 1 \\
\hline
\end{tabular}

VSD, Ventricular septal defect; CAVSD, complete atrioventricular septal defect; TOF, tetralogy of Fallot; TGA, transposition of the great arteries; $S V$, single ventricle; $D I L V$, double inlet left ventricle; $T A$, tricuspid atresia; $T A P V C$, total anomalous pulmonary vein connection; $A o R$, aortic regurgitation; $A S D$, atrial septal defect; $P A V S D$, partial atrioventricular septal defect; $A O S$, aortic stenosis; ALCAPA, anomalous origin of coronary artery from pulmonary artery; cTGA, corrected transposition of the great arteries; WBG, White-Bland-Garland syndrome; PS, pulmonary stenosis.

Definitions of column numbers: 1. junctional ectopic tachycardia; 2. supraventricular tachycardia attacks; 3 . premature supraventricular ventricular contractions; 4. junctional rhythm; 5. sinus bradycardia; 6 . ventricular tachycardia/ventricular fibrillation; 7. premature ventricular contractions; 8. sinus tachycardia; 9. atrioventricular block; 10. atrial fibrillation. 
TABLE 3. Incidences of postoperative arrhythmias assigned to particular types of surgical procedures and Aristotle Basic Score value for each procedure

\begin{tabular}{lccc}
\hline Surgical repair & Arrhythmia & $\%$ & $\begin{array}{c}\text { Aristotle } \\
\text { Basic Score }\end{array}$ \\
\hline ASO repair & $3 / 17$ & 17.6 & 10.0 \\
ASO + VSD repair + VSD & $5 / 6$ & 83.3 & 11.0 \\
$\quad$ closure & & & \\
CAVSD repair & $8 / 17$ & 47.1 & 9.0 \\
TOF repair & $7 / 34$ & 20.6 & 8.0 \\
TAPVC repair & $2 / 4$ & 50 & 5.0 \\
VSD closure & $10 / 77$ & 13 & 6.0 \\
BDCPA & $5 / 17$ & 29.4 & 6.8 \\
AoA & $3 / 8$ & 37.5 & 6.0 \\
AVR & $2 / 3$ & 66.7 & 7.0 \\
WBG & $1 / 4$ & 25 & 10.0 \\
B-T shunt & $2 / 37$ & 5.4 & 6.3 \\
CoA repair & $1 / 28$ & 0.03 & 6.0 \\
ASD closure & $2 / 60$ & 3.3 & 3.0 \\
Rastelli procedure & $1 / 1$ & 100 & 10.0 \\
PAB & $1 / 11$ & 9.1 & 6.0 \\
RVOT procedure & $1 / 1$ & 100 & 6.5 \\
PAPVC scimitar repair & $1 / 1$ & 100 & 8.0 \\
Fontan extracardiac & $1 / 7$ & 14.3 & 9.0 \\
All & $57 / 402$ & 14.2 & \\
\end{tabular}

$A S O$, Arterial switch operation; VSD, ventricular septal defect; CAVSD, complete atrioventricular septal defect; TOF, tetralogy of Fallot; TAPVC, total anomalous pulmonary venous connection; BDPCA, bidirectional cavopulmonary anastomosis; $A o A$, aortic arch repair; $A V R$, aortic valve replacement; $W B G$, White, Bland, Garland syndrome, anomalous origin of coronary artery from pulmonary artery repair; $B-T$, Blalock-Taussig; $C O A$, coarctation of the aorta; $A S D$, atrial septal defect; $P A B$, pulmonary artery banding; RVOT, right ventricular outflow tract; $P A P V C$, partial anomalous pulmonary venous connection.

diagnosed in 6 patients. Permanent pacemakers were implanted in 4 patients. Postoperative AV block was transient and sinus rhythm returned on postoperative days 4 and 5 in 2 patients.

\section{Risk Factor Analysis}

Risk factors for arrhythmias, such as lower age $(P=$ $\left..0041^{*}\right)$, lower body weight $\left(P=.0078^{*}\right)$, higher Aristotle Basic Score $(P=.000001 *)$, longer CPB time $(P=$ $\left..000001^{*}\right)$, longer aortic crossclamp time $\left(P=.000001^{*}\right)$, and use of DHCA $\left(P=.0188^{*}\right)$, were identified in a univariate analysis. In the multivariate stepwise logistic regression only higher Aristotle Basic Score was statistically significant $(P=.000003 *)$ compared with weight $(P=.62)$ and age $(P=.40)$. In the CPB group only longer aortic crossclamp time was statistically significant in the multivariate analysis $(P=.007)$ compared with $\mathrm{CPB}$ time $(P=.9)$, age $(P=.34)$, body weight $(P=.59)$, and Aristotle Basic Score $(P=.22)$.

\section{Discussion}

Various pathophysiologic causes of early postoperative arrhythmias result from direct surgical injury caused by myocardial incision or resulting from cannulation, sutures affecting function of the AV conduction system, and rapid changes of intracardiac pressures caused by volume and pressure fluctuations. ${ }^{13}$ Therefore, although early postoperative cardiac arrhythmias were present in both $\mathrm{CPB}$ and non-CPB groups of the study, the $\mathrm{CPB}$ group was more prone to this type of complication (53/ $299,17.7 \%)$ than the non-CPB group $(4 / 103,3.9 \%)$. In Pfammatter and colleagues' study, ${ }^{6}$ arrhythmic patients were significantly younger than those without arrhythmia. Our results proved similar. In our study, the univariate statistical analysis demonstrated that among younger children with lower body weight arrhythmia occurred significantly more frequently than in older patients. For 3 types of surgical procedures examined by Pfammatter and colleagues (ventricular septal defect closure, tetralogy of Fallot repair, and complete AV canal), the complexity of the procedure was a strong predictor of postoperative arrhythmias. In multivariate stepwise logistic regression analysis, only the Aristotle Basic Score difference was statistically significant in our series, indicating that greater case complexity is associated with a higher incidence of arrhythmias. In the study by Valsangiacomo and colleagues, ${ }^{7}$ the most frequent types of arrhythmia were sinus bradycardia, second and thirddegree AV block, and SVT. In our series JET and SVT were most common. In Valsangiacomo and colleagues' study, lower body weight, longer CPB duration, and higher surgical complexity were the risk factors for early postoperative arrhythmias. The results of our study are similar, identifying lower body weight and age, and higher Aristotle Basic Score as risk factors. In Batra and colleagues' study, ${ }^{14}$ longer ischemic time was the best predictor of JET, which was confirmed by the results of our study. Patients undergoing AV canal repair, arterial switch operation for transposition of the greats arteries, or tetralogy of Fallot repair are at the highest risk of postoperative JET. In our series JET was the most common postoperative arrhythmia (21/57) after AV canal correction $(\mathrm{N}=6)$, ventricular septal defect repair $(\mathrm{N}=$ 5), and arterial switch operation for transposition of the great arteries with ventricular septal defect $(\mathrm{N}=3)$. JET occurred most frequently after tetralogy of Fallot repair in the study by Dodge-Khatami and colleagues, ${ }^{8}$ which our study did not confirm. Early postoperative arrhythmia increased intermittent positive pressure ventilation time and prolonged the ICU postoperative stay of our patients and was associated with higher early postoperative mortality. 


\section{Conclusions}

JET and SVT were the most common postoperative arrhythmias. Lower age, lower body weight, higher ABS, longer CPB time, longer crossclamp time, and use of DHCA are risk factors for postoperative arrhythmias.

\section{References}

1. Yueh-Tze L, Lee J, Wentzel G. Postoperative arrhythmia. Curr $O p$ Cardiol. 2003;18:73-8.

2. Garson A. Chronic postoperative arrhythmias. In: Gillette PC, Garson A, eds. Pediatric Arrhythmias-Electrophysiology and Pacing. Philadelphia: WB Saunders; 1990:667-78.

3. Deanfield J, Camm J, Macartney F, Cartwright T, Douglas J, Drew J, et al. Arrhythmia and late mortality after Mustard and Senning operation for transposition of the great arteries. An eighty-year prospective study. J Thorac Cardiovasc Surg. 1988;96:569-76.

4. Gellatt M, Hamilton RM, McCrindle WB. Risk factors for atrial tachyarrhythmias after the Fontan operation. J Am Coll Cardiol. 1994; 24:1735-41.

5. Vaksmann G, Fornier, Davignon A, Ducharme G, Houyel L, Fouron JC. Frequency and prognosis of arrhythmias after operative correction of tetralogy of Fallot. Am J Cardiol. 1990;66:346-9.

6. Pfammatter JP, Wagner B, Berdat P, Bachmann DC, Pavlovic M, Pfenninger J, et al. Procedural factor associated with early postoperative arrhythmias after repair of congenital heart defects. $J$ Thorac Cardiovasc Surg. 2002;123:258-62.

7. Valsangiacomo E, Schmid ER, Schupbach RW, Schmidlin D, Molinari L, Valdvogel K, et al. Early postoperative arrhythmias after cardiac operation in children. Ann Thorac Surg. 2002;74:792-6.
8. Dodge-Khatami A, Miller OI, Andreson RH, Goldman AP, GilJaurena JM, Elliott M, et al. Surgical substrates of postoperative junctional ectopic tachycardia in congenital heart defects. $J$ Thorac Cardiovasc Surg. 2002;123:624-30.

9. Garson AJ. Diagnostic electrocardiology. In: Anderson RH, Baker E, Macartney F, Rigby M, Shinebourne E, Tynan M, eds. Paediatric Cardiology, 2nd ed. Edinburgh: Churchill Livingstone; 2002: 295-378.

10. Gregoratos G, Abrams J, Epstein AE, Freedman RA, Hayes DL, Hlatky MA, et al. ACC/AHA/NASPE 2002 guideline update for implantation of cardiac pacemakers and antiarrhythmic device: summary article. A report of the American College of Cardiology/American Heart Association Task Force on Practice Guidelines. Circulation. 2002;106:2145-61

11. Jacobs PJ, Jacobs ML, Maruszewski B, Lacour-Gayet F, Robinson Clark D, Tchervenko CI, et al. Current status of the European Association for Cardio-thoracic Surgery and the Society of Thoracic Surgeons Congenital Heart Surgery Database. Ann Thorac Surg. 2005;80: 2278-84.

12. Jacobs JP, Lacour-Gayet FG, Jacobs ML, Robinson Clark D, Tchervenkov CI, Gaynor JW, et al. Initial application in the STS congenital database of complexity adjustment to evaluate surgical casa mix and results. Ann Thorac Surg. 2005;79:1635-49.

13. Herzog L, Lynch C. Arrhythmia accompanying cardiac surgery. In: Lynch C, ed. Clinical Cardiac Electrophysiology. 3rd ed. Philadelphia: JB Lippincott; 1994:231-58.

14. Batra AS, Chun DS, Johnson TR, Maldonado EM, Kashyap BA, Lindbade $\mathrm{CL}$, et al. A prospective analysis of the incidence and risk factors associated with junctional ectopic tachycardia following surgery for congenital heart disease. Pediatr Cardiol. 2006;27: $51-5$ 